\title{
Correlates of age at diagnosis of autism spectrum disorders in six Canadian regions
}

\author{
H. Coo, MSc (1,2); H. Ouellette-Kuntz, MSc (1,2,3); M. Lam, PhD (1); C. T. Yu, PhD (2,4,5); D. Dewey, PhD (2,6,7,8); \\ F. P. Bernier, MD (2,9); A. E. Chudley, MD (2,10,11); P. E. Hennessey, BA (12); M. M. Breitenbach, MSEd (13); \\ A. L. Noonan, MA (14); M. E. Lewis, MD (2,15), J. J. Holden, PhD $(2,3,16,17)$
}

This article has been peer reviewed.

\begin{abstract}
Introduction: Early identification of autism spectrum disorders (ASD) is important, since earlier exposure to behavioural intervention programs may result in better outcomes for the child. Moreover, it allows families timely access to other treatments and supports.

Methods: Using generalized linear modeling, we examined the association between child and family characteristics and the age at which 2180 children were diagnosed with ASD between 1997 and 2005 in six Canadian regions.

Results: A diagnosis of pervasive developmental disorder-not otherwise specified (PDD-NOS) or Asperger syndrome, rural residence, diagnosis in more recent years, and foreign birthplace were associated with a later age at diagnosis. Children who are visible minorities or who have siblings with ASD were more likely to be diagnosed earlier. Collectively, these factors explained little of the variation in age at diagnosis, however.

Conclusion: While it is encouraging that ethnocultural identity, neighbourhood income, urban or rural residence, and sex of the child were not major contributors to disparities in the age when children were identified with ASD, more work is needed to determine what does account for the differences observed. Regional variations in the impact of several factors suggest that aggregating data may not be an optimal strategy if the findings are meant to inform policy and clinical practice at the local level.
\end{abstract}

Keywords: autism spectrum disorder, age at diagnosis, surveillance, Canada, Asperger syndrome, autistic disorder, pervasive child developmental disorder

\section{Introduction}

The Centers for Disease Control and Prevention, the American Academy of Pediatrics and the Canadian Institutes of Health Research all highlight the importance of identifying children with autism spectrum disorders (ASD) at as young an age as possible. ${ }^{1-3}$ A recent review describes the benefits of early diagnosis, ${ }^{4}$ one of which is earlier access to intervention programs. These programs lead to improvements in intellectual functioning and adaptive behaviour. ${ }^{5}$ Earlier exposure increases the likelihood that intervention "will alter the abnormal developmental trajectory of individuals with ASD and help guide brain and behavioural development back toward a normal pathway and, in some cases, prevent the full syndrome of ASD." ${ }^{6}$ This "sooner is better" theory is supported by studies demonstrating that earlier intervention improves outcomes. ${ }^{7,8}$ In Canada, the time it takes to diagnose ASD may also have implications in terms of funding for and hence access to treatment.

\section{Author references}

1. Department of Community Health and Epidemiology, Queen's University, Kingston, Ontario, Canada

2. Autism Spectrum Disorders-Canadian-American Research Consortium (ASD-CARC), Kingston, Ontario, Canada

3. Ongwanada Resource Centre, Kingston, Ontario, Canada

4. Department of Psychology, University of Manitoba, Winnipeg, Manitoba, Canada

5. St. Amant Research Centre, Winnipeg, Manitoba, Canada

6. Department of Pediatrics, University of Calgary, Calgary, Alberta, Canada

7. Department of Community Health Sciences, University of Calgary, Calgary, Alberta, Canada

8. Behavioural Research Unit, Alberta Children's Hospital, Calgary, Alberta, Canada

9. Department of Medical Genetics, University of Calgary, Calgary, Alberta, Canada

10. Medical Genetics Research Group, University of Manitoba, Winnipeg, Manitoba, Canada

11. Department of Pediatrics and Child Health, University of Manitoba, Winnipeg, Manitoba, Canada

12. Department of Health and Community Services, St. John's, Newfoundland and Labrador, Canada

13. Department of Education and Early Childhood Development, Charlottetown, Prince Edward Island, Canada

14. Department of Community Services, Seniors and Labour, Charlottetown, Prince Edward Island, Canada

15. Department of Medical Genetics, University of British Columbia, Vancouver, British Columbia, Canada

16. Department of Psychiatry, Queen's University, Kingston, Ontario, Canada

17. Department of Physiology, Queen's University, Kingston, Ontario, Canada

Correspondence: Hélène Ouellette-Kuntz, Department of Community Health and Epidemiology, Queen's University, 191 Portsmouth Avenue, Kingston, ON K7M 8A6; Tel.: (613) 548-4417; Fax: (613) 548-8135; Email: helene.kuntz@queensu.ca 
For example, in British Columbia the government provides up to $\$ 22,000$ each year to families who have a child with ASD until that child reaches six years of age, at which time funding is reduced to $\$ 6,000$ per year. ${ }^{9}$

There are other benefits to early detection. Parents report feelings of relief when a diagnosis is made, as it gives them a better understanding of their child's behaviour. ${ }^{10}$ A diagnosis also confers eligibility for services and supports and gives parents the option of seeking genetic counselling.

While an ASD diagnosis can often be made reliably when a child is aged between two and three years, ${ }^{11,12}$ many children are not diagnosed until four years of age or more. ${ }^{1,13,14}$ In light of this, national campaigns have been launched in both Canada and the United States (US) to promote earlier detection of ASD. ${ }^{15, *}$

The factors that contribute to variations in age at diagnosis of ASD have not been widely studied, although place seems to play a role. A recent study reported differences in the median age at diagnosis across four regions of Canada, ${ }^{14}$ and a population-based study in the US reported differences across 13 surveillance sites in the age at which children were first identified with ASD. ${ }^{16}$ Results for other factors are less consistent. In one study, boys were identified significantly earlier than girls, ${ }^{16}$ whereas other studies have reported no sex differences in age at diagnosis. ${ }^{17-22}$ Living in a rural area and lower household income were associated with a later age at diagnosis in one survey of 969 caregivers of children with ASD in Pennsylvania, ${ }^{17}$ whereas no significant differences were detected for those same factors in an online survey completed by 146 caregivers of children with ASD in Virginia. ${ }^{18}$ One study that reviewed Philadelphia Medicaid claims found that Caucasian children with autistic disorder were diagnosed significantly earlier than African-American children. ${ }^{22}$ In contrast, the previously mentioned survey of 969 caregivers in Pennsylvania revealed no significant differences in the age at which Caucasian and ethnic minority children were diagnosed. ${ }^{17}$ Similarly, data from the Metropolitan Atlanta Developmental Disabilities Surveillance Program reported no significant effects of race or ethnicity on timing of the ASD diagnosis. ${ }^{13}$

Since the majority of these studies were conducted in the US, it is important to replicate them in other areas with sufficiently large sample sizes to consider multiple factors simultaneously. The analysis presented in this paper used data collected through a Canadian ASD surveillance program. Our objective was to examine the association between child and family characteristics and the age at which children in six regions of Canada were first diagnosed with ASD between 1997 and 2005. A further objective was to explore whether there were any differential effects of the characteristics examined across regions and diagnostic subgroups.

\section{Methods}

\section{Sample}

The sample consisted of 2180 children from six regions of Canada whose information is recorded in the National Epidemiologic Database for the Study of Autism in Canada (NEDSAC). NEDSAC was established in 2001, and surveillance of ASD cases has been ongoing since 2002 among children aged less than 18 years in Manitoba and Prince Edward Island and since 2003 among children aged less than 15 years in southeastern Ontario ${ }^{\dagger}$ and Newfoundland and Labrador. In 2002, three provincial referral and assessment centres in Vancouver, British Columbia, undertook a chart review to identify ASD cases among children aged less than 15 years. Information on diagnosed cases continued to be collected through chart review until 2007, at which time data collection in British Columbia ceased. From 2003 to 2006, the Developmental Clinic at Alberta Children's Hospital in Calgary and various community sources in that city also provided data to NEDSAC on children with ASD aged less than 15 years. More detailed information about the regional case ascertainment and data collection protocols is available in a status report published in this issue. ${ }^{23}$

To compensate for the different start dates and target age groups in the surveillance regions, the sample included children born in 1989 or later who were first diagnosed with ASD before their fifteenth birthday. We also restricted the sample to those who were initially diagnosed between 1997 and 2005, inclusive; relatively few children were diagnosed prior to 1997 , and the last complete year of data collection for Calgary was 2005. Figure 1 illustrates the sample selection process.

\section{Analysis}

NEDSAC contains basic demographic and diagnostic information on children with ASD. We examined the following characteristics in terms of potential associations with age at diagnosis:

(1) diagnostic subgroup (autistic disorder/ pervasive developmental disorder-not otherwise specified [PDD-NOS]/Asperger syndrome/autism spectrum disorder; the latter category was used when a general diagnosis of ASD was provided to the parent or recorded on the child's file);

(2) ethnocultural identity, either selfidentified by parents or recorded on the child's file (Caucasian/visible minority/Aboriginal; when a child is a member of a non-Aboriginal visible minority and also identified as Aboriginal, he or she was classified as Aboriginal);

(3) being adopted (no/yes);

(4) neighbourhood median household income as a proxy measure of household income (lowest/middle/ highest tertile, based on information from the Canadian Census for all private households in the area delineated by the first three characters of the postal code of last known residence in the surveillance region ${ }^{24}$ );

(5) last known residence in the surveillance region (urban/rural, as defined by the second character of the postal code, where a " 0 " was coded as rural and all other numbers were coded as $\operatorname{urban}^{25}$ ); 
FIGURE 1

\section{Sample selection}

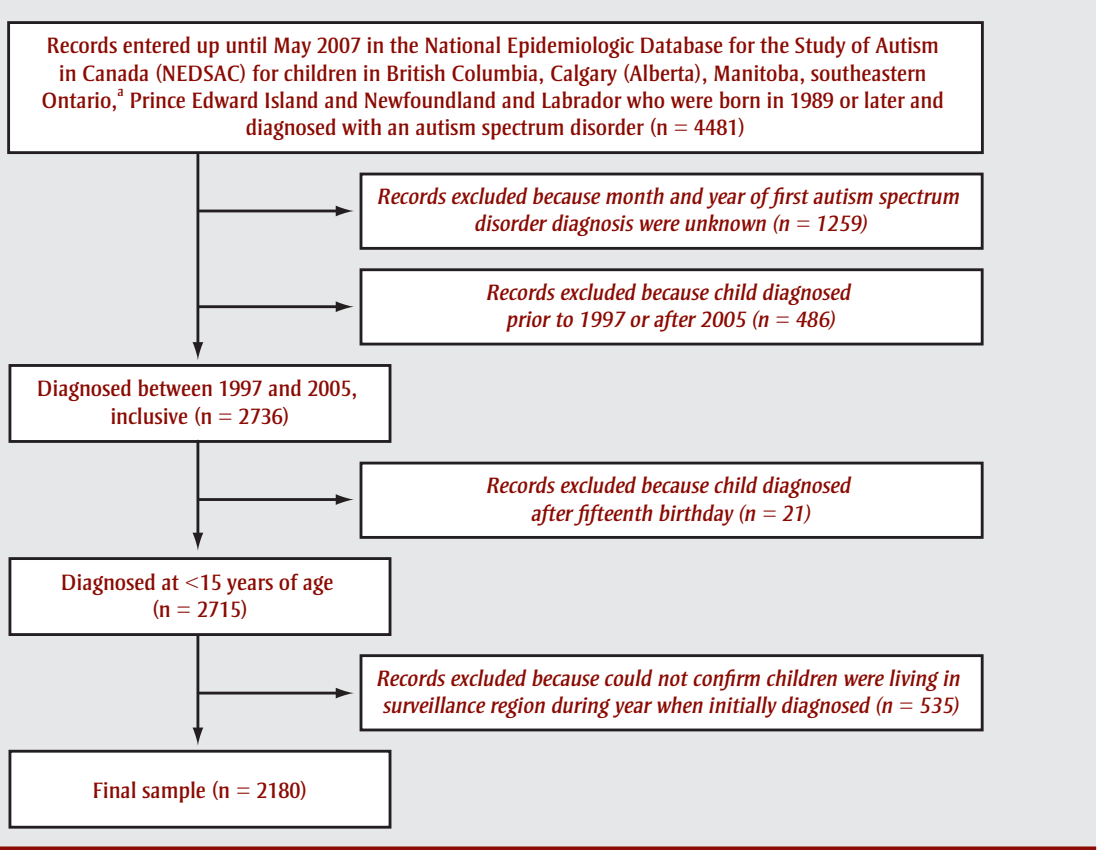

${ }^{a}$ Includes the six counties of Hastings, Prince Edward, Lennox \& Addington, Frontenac, Leeds \& Grenville and Lanark.

(6) sex (boy/girl);

(7)three-year category for year of initial diagnosis(1997-1999/2000-2002/ 2003-2005);

(8) birthplace (Canada/other country); and

(9) whether any siblings have been diagnosed with ASD (no/yes).

Region was entered as a covariate in the models to control for its effects on age at diagnosis, but it was not one of the variables under investigation. Accordingly, we have not reported results for region in the tables or text. A priori, we decided to include only main effects in the regression models and did not test for interactions between the variables.

Generalized linear regression models were fit for the total sample using statistical package SAS version 9.1.3 (SAS Institute Inc.) and specifying the log link function and gamma distribution. ${ }^{26}$ To reduce assumptions regarding the distribution of the dependent variable (age at diagnosis), we used the quasi-likelihood (or generalized estimating equation) approach instead of the full likelihood approach. The first model included only those observations where complete information was available ("complete-case model"). Some of the variables we examined had a large number of missing values (see Table 1; missing values ranged from none for diagnostic subgroup, sex and year of initial diagnosis to $22.9 \%$ for ethnocultural identity). Although imputation methods have their limitations, the current statistical literature recommends that missing values be imputed rather than restricting the analysis to cases with complete data. ${ }^{27}$ We used the Markov chain Monte Carlo method ${ }^{28}$ to generate 10 imputations for each missing data point. Imputed values were not rounded. ${ }^{29}$ Generalized linear regression models were then fit to the imputed data and the final parameter estimates were summarized using the SAS PROC MIANALYZE procedure ("imputed models"). $R^{2}$ values, which in linear regression are used to indicate how much of the variation in the dependent variable is explained by the independent variables, were calculated using the following formula: 1- (raw residual sum of squares)/(total sum of squares). ${ }^{30}$

We then fit separate regression models for the British Columbia and Manitoba data to examine whether the effects of the independent variables varied between those regions. The other four regions were not included in this analysis because the cell counts for certain variables were insufficient to produce meaningful parameter estimates. We also fit separate models for the three diagnostic subgroups ("autism spectrum disorder" was excluded from this analysis) using a forward stepwise variable selection procedure and specifying a $p$-value less than .10 for entering and retaining variables in the model.

All references to significance are based on two-tailed tests using an alpha of .05.

\section{Results}

Table 1 shows frequency distributions as well as mean and median ages at diagnosis for the independent variables. All variables were retained in the models for the total sample and for the British Columbia and Manitoba subsamples, as the variance inflation factors and condition indices were below values indicating potential problems with multicollinearity. ${ }^{31,32}$ Tables 2 and 3 give the exponentiated parameter estimates from the regression models, with the significant findings bolded. Each estimate is the ratio of the expected age at diagnosis relative to the reference category. For example, the exponentiated parameter estimate for Asperger syndrome is 1.72 (Table 2, imputed models). This indicates that children with Asperger syndrome were, on average, diagnosed 1.72 times later than children with autistic disorder (the reference category) when all the other variables were held constant.

For the total sample, a diagnosis of PDD-NOS or Asperger syndrome, rural residence (imputed models), more recent diagnosis, and foreign birthplace were significantly associated with a later age at diagnosis. Conversely, children from visible minority groups or with a sibling with ASD were diagnosed significantly earlier (Table 2). Most of the variables that were significant for the total sample remained significant for the British Columbia subsample, apart from living in a rural area (Table 3). Only PDD-NOS, Asperger syndrome and Aboriginal identity (imputed models) were significantly associated with age at diagnosis for the Manitoba subsample (Table 3). When models were fit for the diagnostic 
TABLE 1

Frequency distribution and mean and median ages at diagnosis for independent variables included in multiple regression analyses to examine associations with age at first diagnosis of an autism spectrum disorder (ASD)

\begin{tabular}{|c|c|c|c|c|}
\hline \multirow[t]{2}{*}{ Independent variables } & \multicolumn{2}{|c|}{$\begin{array}{l}\text { Total sample } \\
(\mathrm{N}=2180)\end{array}$} & \multicolumn{2}{|c|}{ Age at diagnosis } \\
\hline & $\begin{array}{c}\text { Number, } \\
\mathbf{n}\end{array}$ & $\begin{array}{c}\text { Frequency, } \\
\% \\
\end{array}$ & $\begin{array}{c}\text { Mean, } \\
\text { months (SD) }\end{array}$ & $\begin{array}{c}\text { Median, } \\
\text { months (IQ range) }\end{array}$ \\
\hline Total & 2180 & 100.0 & $60.8(32.4)$ & $50.0(37.0)$ \\
\hline \multicolumn{5}{|l|}{ Diagnostic subgroup } \\
\hline Autistic disorder ${ }^{\mathrm{a}}$ & 852 & 39.1 & 57.7 (31.9) & $48.0(29.0)$ \\
\hline PDD-NOS & 320 & 14.7 & $69.2(32.3)$ & $60.0(44.8)$ \\
\hline Asperger syndrome & 164 & 7.5 & $94.0(29.8)$ & $92.0(46.5)$ \\
\hline $\mathrm{ASD}^{\mathrm{c}}$ & 844 & 38.7 & $54.3(28.8)$ & $45.0(27.0)$ \\
\hline \multicolumn{5}{|l|}{ Ethnocultural identity } \\
\hline Caucasian & 1142 & 52.4 & $60.3(32.6)$ & $50.0(38.0)$ \\
\hline Visible minority $^{\mathrm{d}}$ & 467 & 21.4 & $57.7(30.3)$ & $47.0(28.0)$ \\
\hline Aboriginal $^{\mathrm{e}}$ & 72 & 3.3 & $67.7(36.2)$ & $52.5(55.5)$ \\
\hline Unknown & 499 & 22.9 & $63.9(33.2)$ & $53.0(42.0)$ \\
\hline \multicolumn{5}{|l|}{ Adopted } \\
\hline No & 2101 & 96.4 & $60.4(32.0)$ & $50.0(36.0)$ \\
\hline Yes & 58 & 2.7 & $75.6(42.1)$ & $64.0(77.5)$ \\
\hline Unknown & 21 & 1.0 & $58.7(34.0)$ & $48.0(34.5)$ \\
\hline \multicolumn{5}{|c|}{ Neighbourhood median household income $\mathrm{f}^{\mathrm{f}}$} \\
\hline Lowest tertile & 741 & 34.0 & $59.5(31.7)$ & $48.0(36.0)$ \\
\hline Middle tertile & 738 & 33.9 & $61.4(32.4)$ & $51.0(37.0)$ \\
\hline Highest tertile & 683 & 31.3 & $61.5(33.1)$ & $51.0(39.0)$ \\
\hline Unknown & 18 & 0.8 & $63.9(38.7)$ & $55.0(42.5)$ \\
\hline \multicolumn{5}{|c|}{ Last known residence in surveillance region ${ }^{g}$} \\
\hline Urban & 1835 & 84.2 & $60.6(32.5)$ & $50.0(38.0)$ \\
\hline Rural & 336 & 15.4 & $61.5(31.8)$ & $51.0(37.8)$ \\
\hline Unknown & 9 & 0.4 & $71.4(50.8)$ & $52.0(76.5)$ \\
\hline \multicolumn{5}{|l|}{ Sex } \\
\hline Boy & 1809 & 83.0 & $60.6(32.1)$ & $50.0(36.0)$ \\
\hline Girl & 371 & 17.0 & $61.8(34.0)$ & $49.0(39.0)$ \\
\hline \multicolumn{5}{|c|}{ Year of initial diagnosis, three-year category } \\
\hline 1997-1999 & 363 & 16.7 & $50.4(19.8)$ & $46.0(23.0)$ \\
\hline $2000-2002$ & 796 & 36.5 & $57.7(30.3)$ & $48.5(34.0)$ \\
\hline 2003-2005 & 1021 & 46.8 & $66.9(36.2)$ & $54.0(49.0)$ \\
\hline \multicolumn{5}{|l|}{ Country of birth } \\
\hline Canada & 1867 & 85.6 & $58.2(30.6)$ & $48.0(32.0)$ \\
\hline Other & 76 & 3.5 & $83.0(40.7)$ & 73.0 (72.8) \\
\hline Unknown & 237 & 10.9 & $74.0(37.7)$ & $63.0(55.5)$ \\
\hline \multicolumn{5}{|l|}{ Sibling(s) with an ASD } \\
\hline No & 1853 & 85.0 & $61.4(32.5)$ & $51.0(38.0)$ \\
\hline Yes & 209 & 9.6 & $53.2(28.5)$ & $46.0(29.5)$ \\
\hline Unknown & 118 & 5.4 & 65.5 (36.9) & $50.0(55.0)$ \\
\hline
\end{tabular}

Continued on the following page 
TABLE 1 (Continued)

Frequency distribution and mean and median ages at diagnosis for independent variables included in multiple regression analyses to examine associations with age at first diagnosis of an autism spectrum disorder (ASD)

\begin{tabular}{|c|c|c|c|c|}
\hline \multirow[t]{2}{*}{ Independent variables } & \multicolumn{2}{|c|}{$\begin{array}{l}\text { Total sample } \\
(\mathbf{N}=2180)\end{array}$} & \multicolumn{2}{|c|}{ Age at diagnosis } \\
\hline & $\begin{array}{l}\text { Number, } \\
\text { n }\end{array}$ & $\begin{array}{l}\text { Frequency, } \\
\%\end{array}$ & $\begin{array}{l}\text { Mean, } \\
\text { months (SD) }\end{array}$ & $\begin{array}{l}\text { Median, } \\
\text { months (IQ range) }\end{array}$ \\
\hline \multicolumn{5}{|l|}{ Region } \\
\hline British Columbia & 1247 & 57.2 & $64.7(34.0)$ & $54.0(43.0)$ \\
\hline Calgary, Alberta & 180 & 8.3 & $54.1(28.3)$ & $46.0(34.0)$ \\
\hline Manitoba & 493 & 22.6 & $56.2(29.8)$ & $47.0(29.0)$ \\
\hline Southeastern Ontario ${ }^{\mathrm{h}}$ & 116 & 5.3 & $63.8(32.8)$ & $54.0(51.0)$ \\
\hline Prince Edward Island & 54 & 2.5 & $57.7(31.5)$ & $45.5(37.5)$ \\
\hline Newfoundland and Labrador & 90 & 4.1 & $43.3(18.6)$ & $39.0(16.5)$ \\
\hline \multicolumn{5}{|c|}{$\begin{array}{l}\text { Abbreviations: ASD, autism spectrum disorder; IQ, interquartile; NEDSAC, National Epidemiologic Database for the Study of Autism in Canada; } \\
\text { PDD-NOS, Pervasive developmental disorder-not otherwise specified; SD, standard deviation. }\end{array}$} \\
\hline \multicolumn{5}{|c|}{ a Includes children diagnosed with childhood autism and infantile autism. } \\
\hline \multicolumn{5}{|c|}{ b Includes children diagnosed with childhood onset pervasive developmental disorder, atypical autism and other pervasive developmental disorders. } \\
\hline \multicolumn{5}{|c|}{ c General diagnosis of autism spectrum disorder was provided to parents or recorded on child's file. } \\
\hline \multicolumn{5}{|l|}{ d Excludes Aboriginal identity. } \\
\hline \multicolumn{5}{|c|}{$\begin{array}{l}\text { First Nations/Native American, Inuit or Métis. In Manitoba, the on-reserve population is not included in NEDSAC. Reserves are under federal jurisdiction and are not served by the agency } \\
\text { in Manitoba that identifies cases to NEDSAC. }\end{array}$} \\
\hline
\end{tabular}

subgroups, the only variable that was consistently significant was year of diagnosis. Children in the latter two-thirds of the study period were diagnosed significantly later than children diagnosed between 1997 and 1999 (data not shown). The other variables that showed significant associations in the diagnostic subgroup analysis included the following: being adopted for autistic disorder (point estimate $=1.21 ; 95 \% \mathrm{CI}: 1.01-1.46)$ and PDD-NOS (point estimate $=1.42 ; 95 \%$ CI: 1.11-1.83); foreign birthplace for autistic disorder (point estimate $=1.45$; $95 \%$ CI: 1.22-1.72); and having a sibling with ASD for PDD-NOS (point estimate $=0.79 ; 95 \%$ CI: 0.67-0.93).

\section{Discussion}

Diagnostic subgroup has been associated with age at diagnosis of ASD in several studies. ${ }^{13,17,33,34}$ In our sample too, children with Asperger syndrome or PDD-NOS were generally diagnosed later than children with autistic disorder (Tables 2 and 3). Variations in the age at diagnosis among subgroups may be due to differences in the severity of core ASD symptoms: children with autistic disorder typically have more social, communication and cognitive delays than children with PDD-NOS or Asperger syndrome, ${ }^{34}$ which may elicit earlier concerns on the part of parents or professionals.

We found significant associations between ethnocultural identity and age at diagnosis. Little is known about the influence of cultural factors on when children with ASD are diagnosed. A recent Dutch study reported that ethnic minorities are underrepresented in terms of referrals to ASD assessment centres. ${ }^{35}$ The authors noted that pediatricians may attribute social and communication delays among these children to cultural factors. ${ }^{35}$ Such an explanation is not consistent with our findings of earlier diagnosis among visible minorities in the total sample (Table 2) and in the subsample of cases from British Columbia (Table 3); however, it could partially explain why Aboriginal children tended to be diagnosed later than Caucasian children in Manitoba (Table 3). Mandell et al. found that the impact of ethnicity on age at diagnosis was more pronounced for children on the wider autism spectrum (i.e. those diagnosed with Asperger syndrome or PDD-NOS). ${ }^{19}$ We did not include product terms in the multiple regression models, but we found no significant effects of ethnocultural identity on age at diagnosis when we stratified by diagnostic subgroup (data not shown). Thus, in our sample, the influence of ethnocultural identity on age at diagnosis did not appear to be concentrated at one end of the autism spectrum.

It has also been suggested that the symptoms of ASD in adopted children are apt to be mistakenly attributed to early childhood experiences, thus delaying the diagnosis. ${ }^{17}$ Although we found no association between adoption and age at diagnosis in the total sample or in the British Columbia and Manitoba subsamples, it was significant for the autistic disorder and PDD-NOS subsamples. Thus, future studies that examine factors related to timing of diagnosis should consider including this variable.

In contrast to several American studies, ${ }^{17,21}$ we found no association between income and age at diagnosis in our sample (apart 
TABLE 2

Ratio of expected age at diagnosis of an autism spectrum disorder (ASD) compared to reference category, for total sample

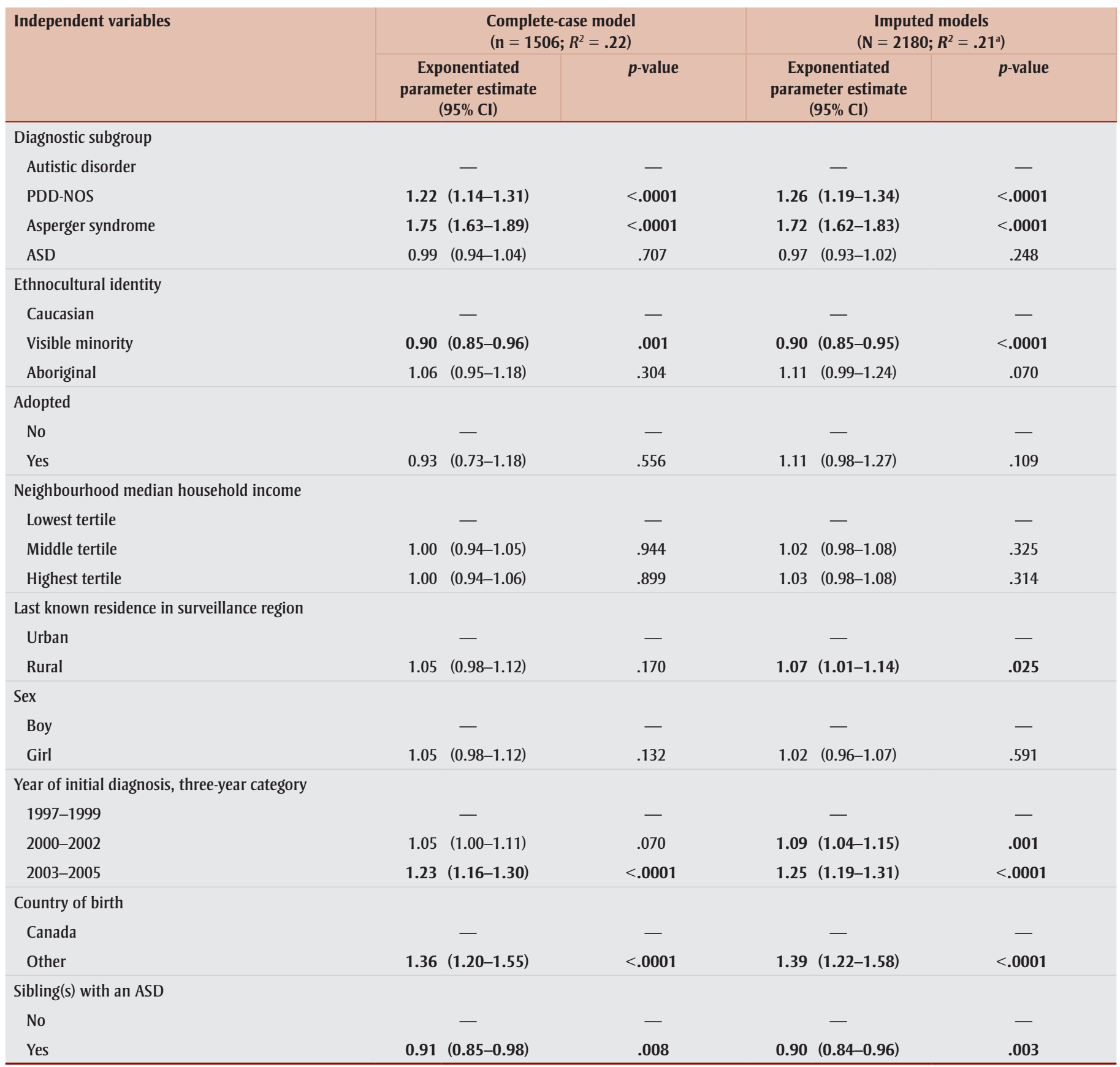

Abbreviations: ASD, autism spectrum disorder; Cl, confidence interval; PDD-NOS, Pervasive developmental disorder-not otherwise specified.

Note: Reference categories are indicated by the long dash. Bolding indicates a statistically significant association based on $p<.05$.

${ }^{a}$ Average $R^{2}$ for 10 datasets with values imputed for missing data points.

from the imputed models for British Columbia, where the association was in the opposite direction from what might be expected: children living in neighbourhoods with the highest median incomes tended to be diagnosed later than children from neighbourhoods with the lowest median incomes). There are two possible explanations for the difference between our findings and those of the American studies. First, the latter used individual-level measures of income, whereas we used a neighbourhood-level measure as a proxy for household income. Second, it is possible that we found no association because there are generally fewer financial barriers to accessing health services in Canada than in the US.
Mandell et al. also reported that children from rural areas tended to be diagnosed with ASD later than children living in urban areas. ${ }^{17}$ They hypothesized that a higher population density contributes to a critical mass of children with ASD, leading to greater familiarity with the disorder on the part of health professionals and families and hence earlier recognition. 
TABLE 3

Ratio of expected age at diagnosis of an autism spectrum disorder (ASD) compared to reference category for British Columbia and Manitoba subsamples

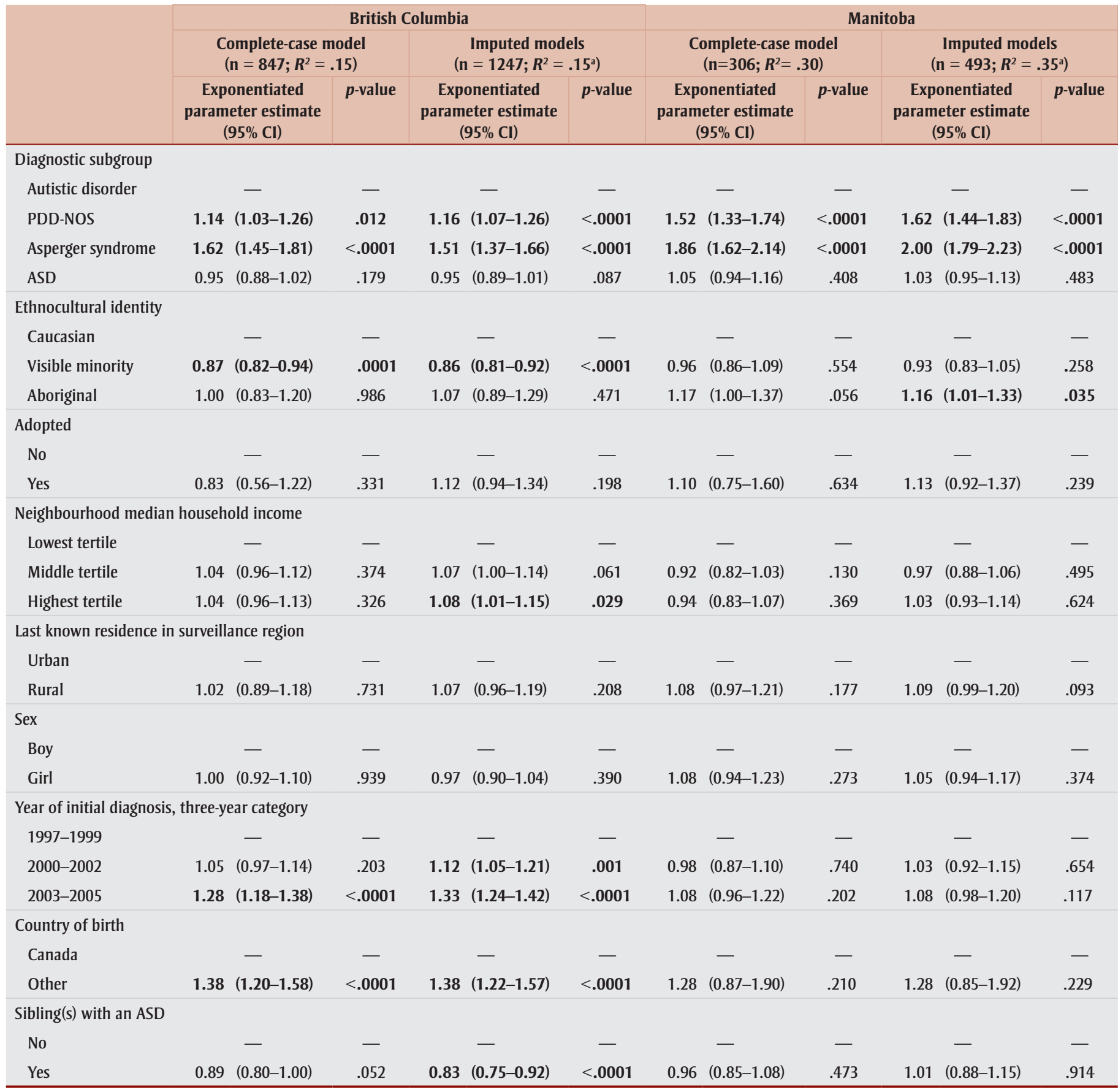

Abbreviations: ASD, autism spectrum disorder; $\mathrm{CI}$, confidence interval; PDD-NOS, Pervasive developmental disorder-not otherwise specified.

Note: Reference categories are indicated by the long dash. Bolding indicates a statistically significant association based on $p<.05$.

${ }^{\text {a }}$ Average $R^{2}$ for 10 datasets with values imputed for missing data points.

Children from rural areas may also face greater barriers in accessing specialized diagnostic services. If the latter is a strong determinant of diagnostic delays, one might expect to see an association between rural status and age at diagnosis in Manitoba: it has a land area of almost $650000 \mathrm{~km}^{2}$ and the two main referral and assessment centres for children with suspected ASD are in Winnipeg. However, while children in rural areas tended to be diagnosed later than those in urban areas in all the models, the association was only significant in the imputed models for the total sample. Future studies could examine the distance to specialized referral and assessment centres instead of urban versus rural residence, something we could not do because our database does not contain addresses. 
With a larger number of girls than boys in our sample $(n=371)$ and the lack of an association between sex and age at diagnosis across all analyses, we found no evidence of what Shattuck et al. referred to as "sex bias in cultural expectations of children's behaviour or in clinical practices for screening, referral and diagnosis." 16 A less encouraging finding is that the age at diagnosis increased over the study period in the total sample, although the data from British Columbia, the region with the largest sample size, may have been the prime driver of this trend; no significant increase was detected in Manitoba (Table 3). (A temporal increase in the age at diagnosis of ASD has also been reported for southeastern Ontario. ${ }^{14}$ ) Children were diagnosed about $25 \%$ later in 2003 to 2005 compared to 1997 to 1999 (Table 2). A similar pattern was seen across all diagnostic subgroups (data not shown), and therefore it is unlikely that this finding can be attributed solely to increased referrals of older children with milder symptoms in the later years of the study period. It may be that assessment services in some regions were becoming overburdened due to increased referrals over the study period, resulting in longer wait times. While we do not have the data to examine this hypothesis, the Standing Senate Committee on Social Affairs, Science and Technology, in its 2007 report on the enquiry into funding ASD treatment in Canada, noted that parents of children with ASD frequently have difficulty accessing assessment and diagnostic services in a timely manner. ${ }^{36}$

Two factors we examined-birthplace and having a sibling with ASD-have not, to our knowledge, been included in other studies of age at diagnosis of ASD. Children born in another country were more likely to be diagnosed at a later age than Canadian-born children. This variable had one of the largest effects, second only to a diagnosis of Asperger syndrome (Table 2). It would be interesting to study this association in a larger sample with more discrete categories for birthplace. The findings could provide a basis for recommendations to improve screening and assessment services among groups that may be at risk for later identification, thus ensuring that all children with ASD are diagnosed as early as possible.
Having a sibling with ASD was associated with an earlier age at diagnosis in the total sample and in British Columbia (Tables 2 and 3), although this variable was only significant for the PDD-NOS subgroup. This suggests that the milder symptoms of PDD-NOS may elicit earlier concerns if the child has a sibling who has already been diagnosed with ASD, whereas the symptoms of autistic disorder may be severe enough that parents or professionals are likely to become concerned early on regardless of whether there is another child with ASD in the family. If this hypothesis is correct, one would expect this variable to be significant for Asperger syndrome as well; however, it was not. This may be due to the small number of children in that group who had a sibling with ASD $(n=16)$. To better evaluate this hypothesis, it would be useful in future studies to include information on whether siblings are older or younger (we did not collect this information in NEDSAC prior to 2009).

One of our objectives was to determine whether the factors we examined for the total sample had a differential effect on age at diagnosis at the regional level. The only significant associations common to both British Columbia and Manitoba were for diagnostic subgroup (Table 3). This underscores the need to consider how aggregating data may obscure regional differences. If the findings from similar analyses are meant to inform policy and clinical practice at the local level, analytic strategies should be employed with this goal in mind. This is particularly relevant in Canada, where diagnostic services vary widely across jurisdictions. For example, in 2003 the provincial government in British Columbia established a provincewide network of clinicians who use standardized guidelines to assess and diagnose children and youth suspected of having ASD. In contrast, the main referral and assessment centres in Manitoba are located in Winnipeg. Thus, it is not surprising that the factors that influence when a child is diagnosed with ASD differ between these provinces.

The $R^{2}$ values indicate that the variables we examined accounted for little of the variation in age at diagnosis $(15 \%-35 \%$;
Tables 2 and 3 ). In some ways, this is reassuring; it suggests that sociodemographic and socio-economic characteristics do not greatly influence when a child is diagnosed with ASD in Canada. It does mean, however, that more work needs to be done to identify what does account for the observed differences in age at diagnosis. Mandell et al. regressed a large number of individual-level variables on age at diagnosis, including ASD symptoms; whether the child had an intellectual disability, hearing impairment or seizures; how many physicians were seen before the diagnosis; whether developmental tests were conducted; and whether there was a referral to a specialist. ${ }^{17}$ In their model, $46 \%$ of the variation in age at diagnosis remained unaccounted for. At least two studies have examined the influence of area-level factors on age at diagnosis. ${ }^{19,21}$ In both these studies, most of the variation in age at diagnosis was associated with differences at the individual level. However, the area-level factors examined were primarily socio-economic and sociodemographic in nature. In future studies, we would like to explore whether health system characteristics are major determinants of when children with ASD are diagnosed. Such characteristics might include the number of developmental pediatricians per capita, the average age of pediatricians practicing in the area, whether practice parameters are in place for screening for ASD, and average wait times for assessment.

\section{Limitations and strengths}

One limitation of this study is the lack of clinical data on cognitive status, comorbidities and ASD symptoms, which have been shown in several US studies to be significantly associated with age at diagnosis. ${ }^{16,17}$ Furthermore, while our surveillance protocols were designed to capture most children diagnosed with ASD in Manitoba, southeastern Ontario, Prince Edward Island, and Newfoundland and Labrador, the data from British Columbia and Calgary are primarily clinicbased, and therefore the extent of our case ascertainment in those regions is unknown. Another potential limitation concerns the multiple imputation procedure in SAS, which assumes that values are missing at random. It is not usually possible to test 
this, but erroneous assumptions in this regard may have a minor impact on parameter estimates and standard errors. ${ }^{37}$ The Markov chain Monte Carlo algorithm assumes multivariate normality to impute missing values. It has been demonstrated, however, that it generally performs well for categorical variables if the imputed values are not rounded, ${ }^{29}$ which was the approach we used.

As shown in Figure 1, we excluded cases where the month and year of initial diagnosis were unknown (thus preventing us from calculating age at diagnosis) and cases where residence in the surveillance regions during the year of initial diagnosis could not be confirmed. We do not know what proportion of these cases would have met the criteria for inclusion in the sample; however, there is no reason to suspect that children who were diagnosed from 1997 to 2005 and who were not included in this analysis for any of the preceding reasons differed systematically from the sample in terms of both the independent variables and the age at which they were diagnosed with ASD. Nevertheless, we cannot rule out the possibility of bias in our estimates. Accordingly, this work needs to be replicated in other samples; our findings can help guide such research.

The strengths of this study include the large sample size, which provided good statistical power to examine the association between a number of factors and the age at which children were diagnosed with ASD. To our knowledge, this is the first study to examine foreign birthplace (for the child) and the presence of a sibling with ASD in relation to age at diagnosis, and it is the first analysis of its kind in a Canadian population. The large sample sizes for British Columbia and Manitoba allowed us to conduct separate analyses for those two regions, which revealed some potentially important differences in how certain factors relate to age at diagnosis at the regional level. Another strength of our analysis is that we only included children who resided in the surveillance regions at the time of diagnosis. This increases the probability that the findings reflect the local diagnostic situation during the study period.

Perhaps one of the most intriguing findings is how little of the variation in age at diagnosis was accounted for by our models. While this suggests that the socioeconomic and sociodemographic factors we examined had little impact on when children with ASD were identifiedwhereas a recent American study found that such factors were generally stronger predictors of age at diagnosis than symptom severity ${ }^{21}$ - it does underscore the need to gain a better understanding of what contributes to disparities in age at diagnosis. Future studies should include more detailed information on the variables we examined, as well as a broader range of factors. These might include individuallevel characteristics, such as the presence of clinical comorbidities that could conceivably delay recognition of the behavioural symptoms of ASD, ${ }^{38}$ as well as health system characteristics, such as waiting times for referral and assessment. Such studies are crucial for ensuring earlier access to treatment and supports for all children with ASD and their families.

\section{Acknowledgements}

We gratefully acknowledge the families and agencies in each region that provide information for the National Epidemiologic Database for the Study of Autism in Canada (NEDSAC). A list of agencies and partners can be viewed at www.nedsac.ca. We also wish to thank Children's Special Services, Manitoba Family Services and Consumer Affairs for their assistance in data collection; Robert Gauthier and Lori Crews, former NEDSAC Regional Co-Directors in Newfoundland and Labrador; the Autism Calgary Association; the Society for Treatment of Autism; Developmental Clinics at the Alberta Children's Hospital; Dr. Jean François Lemay, Department of Pediatrics, University of Calgary and Alberta Children's Hospital; and members of the British Columbia Autism Spectrum Interdisciplinary Research
(ASPIRE) Program (Director - MES Lewis; supported by a Michael Smith Foundation for Health Research Scholar Award) for their support and assistance. The findings and interpretations expressed in this paper are those of the authors and do not necessarily reflect the opinions of the individuals or agencies that provided data for this project.

This work was supported by an Interdisciplinary Health Research Team Grant from the Canadian Institutes for Health Research (\#43820) to the Autism Spectrum Disorders-Canadian-American Research Consortium (ASD-CARC: www. asdcarc.com; J.J.A. Holden, Principal Investigator), and by an Operating Grant from the Canadian Institutes for Health Research (\#79556) to H. Ouellette-Kuntz.

\section{References}

1. Autism and Developmental Disabilities Monitoring Network Surveillance Year 2002 Principal Investigators. Centers for Disease Control and Prevention. Prevalence of autism spectrum disorders-Autism and Developmental Disabilities Monitoring Network, 14 sites, United States, 2002. MMWR. 2007;56(SS01):12-28.

2. Johnson CP, Myers SM, American Academy of Pediatrics Council on Children With Disabilities. Identification and evaluation of children with autism spectrum disorders. Pediatrics 2007;20(5):1183-215.

3. Canadian Institutes of Health Research. Health Research: Key to improving outcomes for children with autism [Internet]. Ottawa (ON): Canadian Institutes of Health Research; 2007 [cited 2010 Feb 8]. Available from: http://www.cihr-irsc.gc.ca/e/32738 .html

4. Barbaro J, Dissanayake C. Autism spectrum disorders in infancy and toddlerhood: a review of the evidence on early signs, early identification tools, and early diagnosis. J Dev Behav Pediatr. 2009;30(5):447-59.

5. Eldevik S, Hastings RP, Hughes JC, Jahr E, Eikeseth S, Cross S. Meta-analysis of Early Intensive Behavioral Intervention for children with autism. J Clin Child Adolesc Psychol. 2009;38(3):439-50. 
6. Dawson G. Early behavioral intervention, brain plasticity, and the prevention of autism spectrum disorder. Dev Psychopathol. 2008;20(3):775-803.

7. Fenske EC, Zalenski S, Krantz PJ, McClannahan LE. Age at intervention and treatment outcome for autistic children in a comprehensive intervention program. Anal Intervention Dev Dis. 1985;5(1-2):49-58.

8. Harris SL, Handleman JS. Age and IQ at intake as predictors of placement for young children with autism: a four- to six-year follow up. J Autism Dev Disord. 2000;30(2):137-42.

9. British Columbia Ministry of Children and Family Development. Fact sheet: Autism spectrum disorder [Internet]. Victoria (BC): British Columbia Ministry of Children and Family Development; 2010 [cited 2011 Jun 24]. Available from: http://www.mcf.gov.bc.ca /spec_needs/pdf/Factsheet_Autism _Jan \%202010_FNL.pdf

10. Midence K, O'Neill M. The experience of parents in the diagnosis of autism: a pilot study. Autism. 1999;3(3):273-85.

11. Cox A, Klein K, Charman T, Baird G, Baron-Cohen S, Swettenham J, et al. Autism spectrum disorders at 20 and 42 months of age: stability of clinical and ADI-R diagnosis. J Child Psychol Psychiatry. 1999;40(5):719-32.

12. Moore V, Goodson S. How well does early diagnosis of autism stand the test of time? Follow-up study of children assessed for autism at age 2 and development of an early diagnostic service. Autism. 2003;7(1):47-63.

13. Wiggins LD, Baio J, Rice C. Examination of the time between first evaluation and first autism spectrum diagnosis in a populationbased sample. J Dev Behav Pediatr. 2006;27(2 Suppl):S79-S87.

14. Ouellette-Kuntz HM, Coo H, Lam M, Yu CT, Breitenbach MM, Hennessey PE, et al. Age at diagnosis of autism spectrum disorders in four regions of Canada. Can J Public Health. 2009;100(4):268-73.
15. Offord Centre for Child Studies. The sooner you know, the sooner you can help: CAIRN launches awareness campaign to identify autism earlier [Internet]. Hamilton (ON): Offord Centre for Child Studies; 2004 [cited 2008 Jan 10]. Available from: http:// www.offordcentre.com/asd/asd_art3.html

16. Shattuck PT, Durkin M, Maenner $M$, Newschaffer C, Mandell DS, Wiggins L, et al. Timing of identification among children with an autism spectrum disorder: findings from a population-based surveillance study. J Am Acad Child Adolesc Psychiatry. 2009;48(5):474-83.

17. Mandell DS, Novak MM, Zubritsky CD. Factors associated with age of diagnosis among children with autism spectrum disorders. Pediatrics. 2005;116(6):1480-6.

18. Rhoades RA, Scarpa A, Salley B. The importance of physician knowledge of autism spectrum disorder: results of a parent survey. BMC Pediatr. 2007;7(37).

19. Mandell DS, Morales KH, Xie M, Lawer LJ, Stahmer AC, Marcus SC. Age of diagnosis among Medicaid-enrolled children with autism, 2001-2004. Psychiatr Serv. 2010;61(8):822-9.

20. Giarelli E, Wiggins LD, Rice CE, Levy SE, Kirby RS, Pinto-Martin J, et al. Sex differences in the evaluation and diagnosis of autism spectrum disorders among children. Disabil Health J. 2010;3 (2):107-16.

21. Fountain C, King MD, Bearman PS. Age of diagnosis for autism: individual and community factors across 10 birth cohorts. J Epidemiol Community Health. 2011;65(6):503-10.

22. Mandell D, Listerud J, Levy SE, Pinto-Martin JA. Race differences in the age at diagnosis among Medicaid-eligible children with autism. J Am Acad Child Adolesc Psychiatry. 2002; 41(12):1447-53.

23. Ouellette-Kuntz H, Coo H, Yu CT, Lewis ME, Dewey D, Hennessey PE, et al. National Epidemiologic Database for the Study of Autism in Canada (NEDSAC). Chronic Dis Inj Can. 2012;32(2):84-9.
24. Statistics Canada. Profile of income of individuals, families and households, social and economic characteristics of individuals, families and households, housing costs, and religion, for Canada, provinces, territories and forward sortation areas, 2001 Census [database]. Ottawa (ON): Statistics Canada; released 2003 Jul 17 (Profile series: 95f0492xcb01003).

25. Statistics Canada. How postal codes map to geographic areas. Glossary [Internet]. Ottawa (ON): Statistics Canada; 2007 [cited 2007 Oct 25]. Available from: http:// www.statcan.ca/english / research /92F0138MIE/2007001/glossary.htm

26. Manning WG, Mullahy J. Estimating log models: to transform or not to transform? J Health Econ. 2001;20(4):461-94.

27. Afifi AA, Kotlerman JB, Ettner SL, Cowan M. Methods for improving regression analysis for skewed continuous or counted responses. Annu Rev Public Health. 2007;28:95-111.

28. SAS Institute. Multiple imputation for missing data [Internet]. Cary (NC): SAS Institute; 2009 [cited 2009 Mar 9]. Available from: http://support.sas.com/rnd/app/da /new/dami.html

29. Allison PD. Paper 113-30. Imputation of categorical variables with PROC MI. Paper presented at: Proceedings of the Thirtieth Annual SAS Users Group International Conference; 2005 Apr 10; Cary (NC).

30. Zheng B. Summarizing the goodness of fit of generalized linear models for longitudinal data. Stat Med. 2000;19(10):1265-75.

31. Katz MH. Multivariable Analysis. A Practical Guide for Clinicians. Cambridge (UK): Cambridge University Press; 2006.

32. SAS Institute. SAS/STAT(R) 9.2 User's Guide, Second Edition [Internet]. Cary (NC): SAS Institute; 2009 [cited 2010 Mar 29]. Available from: http://support.sas .com/documentation/cdl/en/statug/63033 /HTML/default/viewer.htm\#/documentation /cdl/en/statug/63033/HTML/default /statug_reg_sect038.htm 
33. Howlin P, Asgharian A. The diagnosis of autism and Asperger syndrome: findings from a survey of 770 families. Dev Med Child Neurol. 1999;41(12):834-9.

34. Chakrabarti S, Fombonne E. Pervasive developmental disorders in preschool children: confirmation of high prevalence. Am J Psychiatry. 2005;162(6):1133-41.

35. Begeer S, Bouk SE, Boussaid W, Terwogt MM, Koot HM. Underdiagnosis and referral bias of autism in ethnic minorities. J Autism Dev Disord. 2009;39(1):142-8.

36. Eggleton A, Keon WJ. Final Report on the enquiry on the funding for the treatment of autism. Pay now or pay later. Autism families in crisis [Internet]. Ottawa (ON): The Standing Senate Committee on Social Affairs, Science and Technology; 2007 [cited 2007 Nov 6]. Available from: http:// w w w. parl.g c.ca / Con t en t/S E N /Committee/391/soci/rep/repfinmar07-e.htm

37. Schafer JL, Graham JW. Missing data: our view of state of the art. Psychol Methods. 2002;7(2):147-77.

38. Schaefer GB, Mendelsohn NJ. Professional Practice and Guidelines Committee. Clinical genetics evaluation in identifying the etiology of autism spectrum disorders. Genet Med. 2008;10(4):301-5. 